\title{
The 20th Ramanujan Symposium, International Conference on Fourier Analysis and Wavelets (ICFAWL: 2017)
}

\author{
G. P. Youvaraj ${ }^{1}$ \\ Published online: 17 November 2018 \\ (c) Forum D'Analystes, Chennai 2018
}

The 20th Ramanujan Symposium, International Conference on Fourier Analysis and Wavelets (ICFAWL-2017) was organized by The Ramanujan Institute for Advanced Study in Mathematics, University of Madras., during March 21-25, 2017.

The main goal of the conference was meant to provide a platform for experts in Fourier Analysis and Wavelets to meet and interact with each other, and to share their results and ideas. This Conference was also aimed at giving some introduction and an overview of these two areas. The Conference had plenary lectures, Thematic Lectures, Invited talks and also contributed papers. The thematic lectures were aimed at introducing these areas to young scientists and graduate students. Also, this conference was to inculcate the recent developments and new avenues of current research to the participants and inspire them to undertake their research work in these fields.

The organizing committee was pleased that the conference was well attended by the participants from India, Spain, Germany and USA. The lectures in the conference were well received by the participants and discussions were fruitful. We sincerely hope that the meeting had helped many young researchers in sharing their ideas with other experts; and the lectures by the experts have helped to inspire young research scholars and scientists.

This proceeding contains only those papers which are peer reviewed and accepted and a few contributed articles from some experts in the area.

On behalf of the organizing committee, I thank the Vice Chancellor Prof. P. Duraisamy and the Registrar Prof. R. Srinivasan for their support in organizing the conference and bringing out this proceeding. I also thank all of my colleagues, office staff and research scholars for their help and support in conducting this conference successfully. I would like to thank my student Mr. S. Pitchai Murugan, whose meticulous and dedicated help was crucial during the conference and brining out this proceedings.

G. P. Youvaraj

youvarajgp@yahoo.com

1 Ramanujan Institute for Advanced Study in Mathematics, University of Madras, Chennai, India 
Finally, on behalf of the organizing committee, I thank IMU CDC, SERB, IMSc, UGC and INSA for their financial support and Forum D' Analysts for agreeing to publish this proceedings in Journal of Analysis as a part of this issue.

G. P. Youvaraj Ramanujan Institute for Advanced Study in Mathematics, University of Madras. 